\title{
Electrochemical Formation of Cerium Oxide/Layered Silicate Nanocomposite Films
}

\author{
Adele Qi Wang ${ }^{1}$ and Teresa Diane Golden ${ }^{2}$ \\ ${ }^{1}$ Physics Department, Yeshiva University, New York, NY 10016, USA \\ ${ }^{2}$ Department of Chemistry, University of North Texas, 1155 Union Circle \#305070, Denton, TX 76203, USA \\ Correspondence should be addressed to Teresa Diane Golden; tgolden@unt.edu
}

Received 30 June 2016; Accepted 17 November 2016

Academic Editor: Carlos R. Cabrera

Copyright (c) 2016 A. Q. Wang and T. D. Golden. This is an open access article distributed under the Creative Commons Attribution License, which permits unrestricted use, distribution, and reproduction in any medium, provided the original work is properly cited.

\begin{abstract}
Cerium oxide/montmorillonite nanocomposite films were synthesized electrochemically from solutions containing 0.5 to $50 \% \mathrm{Na}$ montmorillonite. The nanocomposites were characterized by X-ray diffraction, scanning electron microscopy, Fourier transform infrared spectroscopy, and Raman spectroscopy. Nanocomposite films synthesized from montmorillonite concentrations lower than $10 \%$ were continuous, uniform, and dense. X-ray diffraction confirmed that the nanocomposite films retain the face-centered cubic structure of cerium oxide while incorporating exfoliated platelets of the montmorillonite into the matrix. In addition, calculations from XRD data showed particle sizes ranging from 4.50 to $6.50 \mathrm{~nm}$ for the nanocomposite coatings. Raman and FTIR spectroscopy had peaks present for cerium oxide and the layered silicates in the coatings. Cross-sectional scanning electron microscopy and energy-dispersive X-ray spectroscopy confirmed the presence of montmorillonite throughout the cerium oxide matrix.
\end{abstract}

\section{Introduction}

Cerium oxide $\left(\mathrm{CeO}_{2}\right)$ is an important ceramic material, with excellent corrosion-resistant properties for metals and alloys [1-7]. Cerium oxide films can also be used in solid oxide fuel cells and have optical applications [8-11]. Thermodynamic stability and reactivity for $\mathrm{CeO}_{2}$ portend promising use of this material in the catalytic industry [12-14]. Also, applications for cerium oxide films can be limited by $\mathrm{CeO}_{2}$ strength and toughness, since it is a ceramic and tends to be brittle. Improving the strength of the film leads to longer lifetime for the protective coatings, and reinforcing the films broadens the application of $\mathrm{CeO}_{2}$ as a corrosion protection film, catalyst, electrode, and buffer layer $[15,16]$. Particle size is integral to the unique properties and applications of cerium oxide. In general, the smaller the particle size, the lower the packing porosity and the higher the surface area. Catalytic activity and electrical conductivity of crystalline cerium oxide depend on particle size, in that electronic conductivity predominates in the nanocrystalline phase, and ionic conductivity mainly controls the microcrystalline structure [17].
One technique to improve the mechanical properties of ceramics is by dispersing nanometer-sized particles into the ceramic-matrix. The reinforcing agents can be spherical, whiskers, short fibers, and platelet structured materials [1821]. Reinforcing mechanisms depend on the properties of the secondary phase within the composite. Examples for particlereinforced ceramic materials include $\mathrm{Al}_{2} \mathrm{O}_{3}$ and $\mathrm{MgO}$ composites toughened with materials such as $\mathrm{TiC}, \mathrm{TiB}_{2}, \mathrm{SiC},(\mathrm{W}$, $\mathrm{Ti}) \mathrm{C}$, and $\mathrm{Ti}(\mathrm{C}, \mathrm{N})[22,23]$. Mullite fiber has been coated with zirconia and then used in the toughening of mullite ceramic composites. SiC monofilament and multifilament Nicalon and $\mathrm{HPZ}$ fibers have been used to reinforce $\mathrm{BaAl}_{2} \mathrm{Si}_{2} \mathrm{O}_{8}$ (BAS) and $\mathrm{SrAl}_{2} \mathrm{Si}_{2} \mathrm{O}_{8}$ (SAS) ceramics $[24,25] . \mathrm{Si}_{3} \mathrm{~N}_{4}$ whiskers can also act as reinforcing phases and can be used in the strengthening of $\mathrm{BAS}, \mathrm{MgO} / \mathrm{CeO}_{2}$, and $\mathrm{SiC}$ [26-28]. Various platelets (e.g., $\mathrm{SiC}, \mathrm{Al}_{2} \mathrm{O}_{3}$, and $\mathrm{ZrB}_{2}$ ) widely applied in the toughening and strengthening of ceramic materials have resulted in obvious improved mechanical properties. Investigation into mechanical properties of $\mathrm{SiC}$ platelet-embedded $\mathrm{Al}_{2} \mathrm{O}_{3}$ composites concluded that both Young's modulus and fracture toughness of the composites with small platelets 
increased with greater $\mathrm{SiC}$ volume fraction [29]. Plateletreinforced Ti-B-C composites also showed higher hardness, flexural strength, and fracture toughness [30].

Platelets reinforce in two dimensions as opposed to other particle shapes; therefore, orientation of the platelet is important when the toughening mechanism is considered. Layered silicates, which are clay platelets, have interesting intercalation and exfoliation properties and can be combined with other media to form composites. The combination of layered silicates with ceramic materials by intercalation has been successful with $\mathrm{SiO}_{2}, \mathrm{TiO}_{2}, \mathrm{ZrO}_{2}$, and $\mathrm{Al}_{2} \mathrm{O}_{3}$ [3134]. Montmorillonite (MMT) layered silicates, when exfoliated, have dimensions that range from 100 to $1000 \mathrm{~nm}$ in length with thickness of only $1-2 \mathrm{~nm}$. This high aspect ratio property confirms the feasibility of dispersing this type of material within the structure matrix, with potentially significant improvements in mechanical properties. For example, addition of $20-35 \%$ of montmorillonite in an alumina composite improved the mechanical strength of alumina [35]. The majority of work has been intercalation of compounds into the layered silicate gallery. Very few articles have studied effects of exfoliated clay addition into another matrix using an electrochemical technique for nanocomposite film formation. Electrochemical synthesis is an ideal technique to suspend a second phase into the matrix and assure improvement of mechanical as well as corrosion-inhibiting properties. Our group has studied the electrochemical addition of nanoclay platelets within metals and alloys for corrosion protective coatings [36-39]. This research presents electrochemical deposition of a ceramic with nanoclay addition, cerium oxide/layered silicate films. The successful synthesis, crystalline structure, morphology, and mechanical properties of the deposited films are studied.

\section{Experimental}

2.1. Materials. Na-montmorillonite (MMT) was provided by Southern Clay Products (Gonzales, TX, USA) and was first delaminated by ultrasonication and stirring for 24 hours before being added to an electrolyte solution. Na-montmorillonite layered silicate was mixed with $0.1 \mathrm{M} \mathrm{Ce}\left(\mathrm{NO}_{3}\right)_{3} \cdot 6 \mathrm{H}_{2} \mathrm{O}$ (Alfa-Aesar) and $0.1 \mathrm{M}$ acetic acid (Fisher) to form the plating solution. Concentrations of the MMT were 1, 2, 3, 5, 10, 20, 30 , and $50 \%\left(\mathrm{w} / \mathrm{w}, \mathrm{MMT} / \mathrm{Ce}\left(\mathrm{NO}_{3}\right)_{3} \cdot 6 \mathrm{H}_{2} \mathrm{O}\right) \cdot \mathrm{pH}$ was adjusted with $\mathrm{NaOH}$ in the range of 7.5-8.0 and was monitored with a $\mathrm{pH}$ meter throughout the deposition experiments. The working electrode was prepared by mounting stainless steel in epoxy; it was then polished to a mirror finish and rinsed and ultrasonicated. Platinum wire or mesh was used as the counter electrode, and a saturated calomel electrode (SCE) was the reference.

2.2. Electrochemical Film Deposition. An EG\&G Princeton Applied Research (PAR) Model 273A potentiostat/galvanostat was used to electrochemically deposit the films. Deposition was conducted in an undivided cell and regular three-electrode configuration. The electrochemical cell was kept at constant temperature with a Fisher Scientific Model
1016D circulator. Anodic electrodeposition with an applied potential of $1.1 \mathrm{~V}$ at $25^{\circ} \mathrm{C}$ was used to deposit the films over 24 hours.

2.3. Characterization. Dynamic light scattering capable of measuring 0.8 to $6500 \mathrm{~nm}$-sized particles in solution was run on a Microtrac Nanotrac ULTRA using a $780 \mathrm{~nm}$ diode laser at $3 \mathrm{~mW}$ power. Nanoindentation was conducted on a NANO III nanoindentator (nanodiamond tip) with an attached Nikon optical microscope (800x magnification) to obtain optical micrographs. A JEOL JSM-T300 scanning electron microscope (SEM) was used to obtain topological morphologies of composite film surfaces and cross sections. The attached TN 5500 X-ray analyzer provided elemental information of detected areas. Structure and phase composition of the electrochemical deposited films were identified by $\mathrm{X}$-ray diffraction (XRD) with a Siemens D500 diffractometer using $\mathrm{Cu} \mathrm{K} \alpha$ radiation $(\lambda=0.15405 \mathrm{~nm})$. The tube source was operated at $40 \mathrm{kV}$ and $30 \mathrm{~mA}$ to produce scans at a $0.02^{\circ}$ step size and $1 \mathrm{sec}$ dwell time. Raman spectra were obtained using a Yvon Dilor XY800 Raman microprobe equipped with a nitrogen-cooled multichannel (CCD) detector with an excited wavelength of $514 \mathrm{~nm}$ laser radiation at $10 \mathrm{~mW}$ of power to prevent local heating of the sample. All spectra were recorded between 200 and $4000 \mathrm{~cm}^{-1}$ with $3 \mathrm{~cm}^{-1}$ spectra resolution, $719 \mathrm{~mm}$ focal length, 600 lines/mm gratings, and $10 \mathrm{x}$ objective focused to $10 \mu \mathrm{m}$ spot size. At least three spectra were collected randomly from different areas of the films and plotted. Infrared spectra were obtained using a PerkinElmer 1760X FTIR spectrophotometer. For each sample, 40 scans were collected in the range of $4000-400 \mathrm{~cm}^{-1}$ with a resolution of $4 \mathrm{~cm}^{-1}$.

\section{Results and Discussions}

Previous studies for pure cerium oxide film formation have reported detection of a small oxidation peak in the cyclic voltammetry $(\mathrm{CV})$ scan that is attributed to the conversion of $\mathrm{Ce}(\mathrm{III})$ to $\mathrm{Ce}(\mathrm{IV})$ species [7]. However, at these conditions, $\mathrm{CeO}_{2}$ films as well as $\mathrm{CeO}_{2}$ powders can be produced. The addition of a ligand (i.e., acetic acid and lactic acid) to the solution results in complexation of cerium ions and favors the slow release of $\mathrm{Ce}^{3+}$ from the Ce-ligand complex during electrodeposition. These $\mathrm{Ce}^{3+}$ free ions are the primary reactant supply for the electrochemical reaction at the electrode. The slow release of $\mathrm{Ce}^{3+}$ ions makes film formation preferred over powder production during the process. The Ce(III)-ligand complex is significant for anodic deposition of the cerium oxide film [7, 40]. Since previous electrochemical conditions have been elucidated for cerium oxide deposition, these conditions were a starting point for composite film depositions. Solution chemistry influences nanocomposite deposition, and important electrochemical parameters include complexing ligand strength, $\mathrm{pH}$ of the deposition solution, and temperature of the deposition solution.

Since the clay charge density is heterogeneous, suspension stability in the plating solution is critical. When the clay 
is dispersed in aqueous medium of near-neutral to alkaline $\mathrm{pH}$, the particles carry a net negative charge, largely due to isomorphic substitution of cations of lower charge for cations of higher charge $\left(\mathrm{Al}^{+3}\right.$ for $\mathrm{Si}^{+4}$ in the tetrahedral sheet and $\mathrm{Fe}^{+2}$ or $\mathrm{Mg}^{+2}$ for $\mathrm{Al}^{+3}$ in the octahedral sheet). Electrostatic surface charge influences distribution of nearby ions in a polar medium. Counter ions are attracted to the surface, while other ions are repelled. Three types of dispersions exist in clay suspensions: formation of an immiscible macroaggregate, swelling of the smectite clays to include a host matrix (intercalated), or separation of the layers (exfoliated). In this work, MMT is exfoliated so that individual platelets are sheared apart from each other and allowed to disperse in the electrolyte solution. Dynamic light scattering studies for the electrolyte solutions show dispersion of the clay in the electrolyte solution. For lower concentrations of montmorillonite (MMT) $(<5 \%)$ in the solution, the measured particle sizes for the platelets range from $\sim 450$ to $750 \mathrm{~nm}$. However, when the MMT concentration is increased $(>10 \%)$ in the electrolyte, the measured particle sizes range from 3000 to $4000 \mathrm{~nm}$, indicating that some agglomeration occurs.

Montmorillonite layered silicates are clays approximately represented by the formula $(\mathrm{Na}, \mathrm{Ca})(\mathrm{Al}$, $\mathrm{Mg})_{6}\left(\mathrm{Si}_{4} \mathrm{O}_{10}\right)_{3}(\mathrm{OH})_{6} \cdot n \mathrm{H}_{2} \mathrm{O}$ (Figure 1$) \cdot \mathrm{Al}^{3+}$ or $\mathrm{Si}^{4+}$ locations can be replaced by lower valent cations, which cause the montmorillonite structure to have an excess of electrons. This negative charge can be satisfied by loosely held cations in the interlayer spacing. Sodium montmorillonite refers to the clay mineral in which loosely held cation is the $\mathrm{Na}^{+}$ion. Individual montmorillonite platelets exist as coordinated layers that are one nanometer thick and several microns wide. The layers are periodically spaced apart, with a repeating distance in the nanometer range, called the gallery spacing. Prior to electrochemical deposition of the nanocomposites, $\mathrm{Na}$-montmorillonite powder is characterized by X-ray diffraction. For reference, Figure 2 shows the resulting pattern from the Na-montmorillonite powder compared to a cerium oxide powder. The $(00 l)$ reflections (representing interlayer spacing) for air-dried clay samples are shifted in 2 -theta and are less intense, which would be expected for this sample, compared to a well-ordered, highly processed sample. Other peaks include the (060) reflection and bands $(02 ; 11),(20 ; 13)$, and $(04 ; 22)$. Since quartz can be an impurity in clay samples, smaller sharp peaks for quartz are present in the pattern. When the layered silicate is exfoliated, there is an absence of or considerable intensity decrease of the clay peaks, since the platelets are not stacked together and do not exhibit long-range order. The cerium oxide powder pattern displays a random orientation that matches the typical fluorite structure for $\mathrm{CeO}_{2}$, and these reflections are used for identification of the cerium oxide composite films.

For nanocomposite film deposition, montmorillonite concentrations from 0.5 to $50 \%$ were added to the electrodeposition solution. Figure 3 shows the XRD patterns of the resulting $\mathrm{CeO}_{2} / \mathrm{MMT}$ nanocomposite films for the montmorillonite content range from 0.5 to $30 \%$ of cerium nitrate $(\mathrm{w} / \mathrm{w})$. Montmorillonite addition in the films does not change the fcc structure of $\mathrm{CeO}_{2}$ and thus indicates an intact matrix of $\mathrm{CeO}_{2}$ in the composites. XRD patterns exhibit only reflection for $\mathrm{fcc} \mathrm{CeO}_{2}$ at lower concentrations of added MMT. As the concentration of montmorillonite increases higher than 5\%, reflections for the MMT in the film emerge at $11.50-12.00^{\circ} 2 \theta$ and confirm some associated stacking of silicate layers. This broad peak corresponds to disordered (00l) reflections for the montmorillonite. Similar results have been seen for layered silicates when large amounts are added to metal deposition solutions [36]. All calculated particle sizes corresponding to the XRD patterns are listed in Table 1. The nanocomposite films have particle sizes in the range of 5$10 \mathrm{~nm}$ as calculated from the FWHM of the $\mathrm{CeO}_{2}$ reflections using the Scherrer equation.

Morphology of as-formed composites was observed using optical microscopy and SEM. Figure 4 shows the picture of a $\mathrm{CeO}_{2} / \mathrm{MMT}$ nanocomposite film. The nanocomposite films have a smooth, homogenous, uniform surface, with the clay incorporated with cerium oxide up to MMT concentrations of 5\%. At higher magnifications using SEM (Figure 5), the coatings are dense and show random, amorphous-like structures on the surface, with good adhesion to the substrate.

Raman spectroscopy of the nanocomposite films (Figure 6) shows the main peak $\left(\mathrm{F}_{2 \mathrm{~g}}\right)$ for cerium oxide at $459 \mathrm{~cm}^{-1}$, a slight negative shift from $465 \mathrm{~cm}^{-1}$, the bulk $\mathrm{CeO}_{2}$ value [41]. The shift is due to the nanocrystallinity of the films, shown earlier to be about $\sim 6 \mathrm{~nm}$ from XRD data (Table 1). The other small peaks around 600-700 and $1000-1100 \mathrm{~cm}^{-1}$ are ascribed to surface oxygen species. The clays have no activity in the Raman frequency region, but, typically with increasing amounts of MMT, the background luminescence increases. Raman spectra were reproducible, demonstrating the homogeneity of the deposited $\mathrm{CeO}_{2} /$ MMT nanocomposite films.

ATR-IR spectra of the nanocomposite films can be used to investigate clay minerals in forms like films, dispersions, gels, or pastes (Figure 7) [42]. A band at $550 \mathrm{~cm}^{-1}$ is a characteristic peak in the phonon modes spectral range for cubic crystalline forms of rare earth oxides like cerium oxide. The peak around $1021 \mathrm{~cm}^{-1}$ is assigned as the first overtone mode of the fundamental vibration at $550 \mathrm{~cm}^{-1}$ and signifies $\mathrm{CeO}_{2}$ in the coating. There are broad absorption bands in the range of 1100 to $1000 \mathrm{~cm}^{-1}$. The peak at $\sim 1080 \mathrm{~cm}^{-1}$ is due to $\mathrm{Si}-\mathrm{O}$ stretching, which is due to the presence of silicates in the clay. Peaks at $\sim 1025 \mathrm{~cm}^{-1}$ and $1045 \mathrm{~cm}^{-1}$ can be ascribed to overlapping of $\mathrm{Si}-\mathrm{O}-\mathrm{Si}$ stretching of montmorillonite. For higher content of clay, the $\mathrm{Si}-\mathrm{O}$ band in clay predominates over the vibrations from cerium oxide. The $\mathrm{Si}-\mathrm{O}$ band is basically centered at $\sim 1045 \mathrm{~cm}^{-1}(50 \%, 30 \%, 20 \%$, and $10 \%)$ MMT. As clay concentration in the nanocomposite becomes lower (e.g., 5\%, 3\%, 2\%, 1\%, and $0.5 \%$ ), the band splits into two peaks, located at $\sim 1046$ and $1023 \mathrm{~cm}^{-1}$, respectively. Bands centered at $\sim 935 \mathrm{~cm}^{-1}$ and $840 \mathrm{~cm}^{-1}$ are due mainly to cerium oxygen bonds. However, there are also vibrations possible at $\sim 914 \mathrm{~cm}^{-1}$ and $847 \mathrm{~cm}^{-1}$ which represent inner hydroxyl bending in $\mathrm{Al}-\mathrm{Al}-\mathrm{OH}$ and in the $\mathrm{Al}-\mathrm{Mg}-\mathrm{OH}$ structure, respectively. The $\mathrm{Al}-\mathrm{Mg}-\mathrm{OH}$ vibration reflects partial magnesium substitution for aluminum in the octahedral 
TABLE 1: Particle sizes of $\mathrm{CeO}_{2} /$ montmorillonite nanocomposite films calculated from XRD patterns using the Scherrer equation for the (111) reflection.

\begin{tabular}{lccccccccccc}
\hline \% Na-MMT & 0.5 & 1 & 2 & 3 & 5 & 10 & 20 & 30 & 40 & 50 & 60 \\
\hline Particle size $(\mathrm{nm})$ & 6.51 & 5.11 & 5.50 & 6.00 & 5.33 & 5.40 & 4.53 & 5.06 & 4.54 & 5.99 & 6.00
\end{tabular}

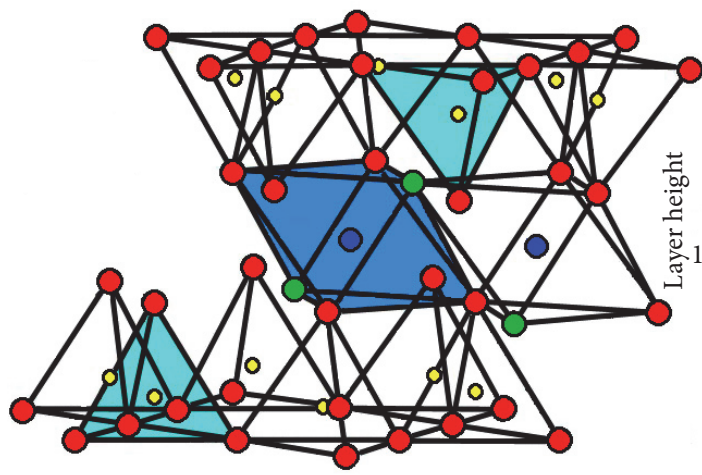

$\mathrm{Na}^{+}$
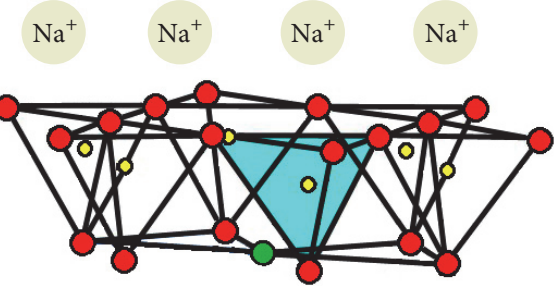

- Silicon

Oxygen
Aluminum

Hydroxyl
Tetrahedral layer

Octahedral layer

Tetrahedral layer

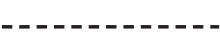

Gallery

Tetrahedral layer

FIGURE 1: Schematic of the montmorillonite layered silicate platelet showing one platelet height and the gallery spacing between layers.

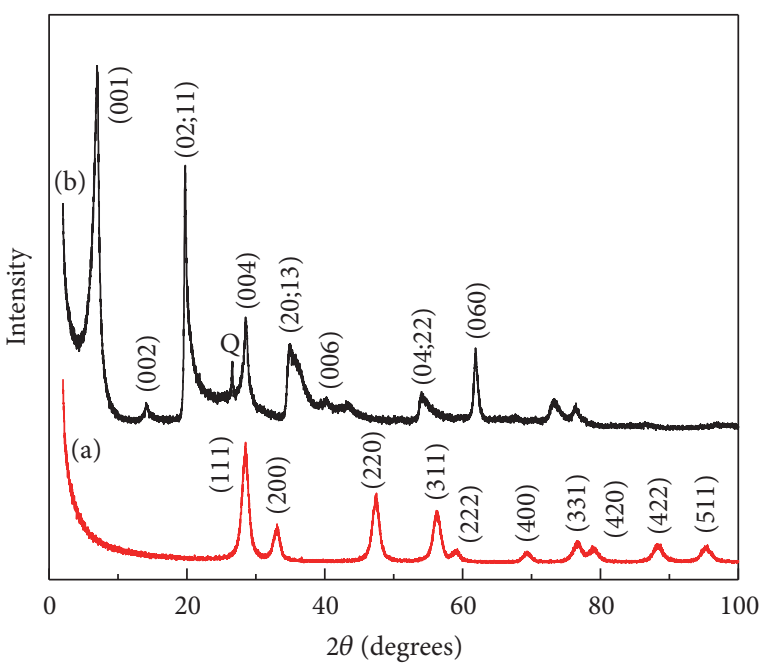

Figure 2: X-ray diffraction patterns of (a) $\mathrm{CeO}_{2}$ powder and (b) $\mathrm{Na}-$ montmorillonite powder.

sheets, and the bands in this region may overlap or be buried in the broad band $[42,43]$.

Incorporation of $1 \%$ by weight of montmorillonite into the $\mathrm{CeO}_{2}$ film leads to an increase in modulus of $\sim 23 \%$. Incorporating secondary phases with higher aspect ratios

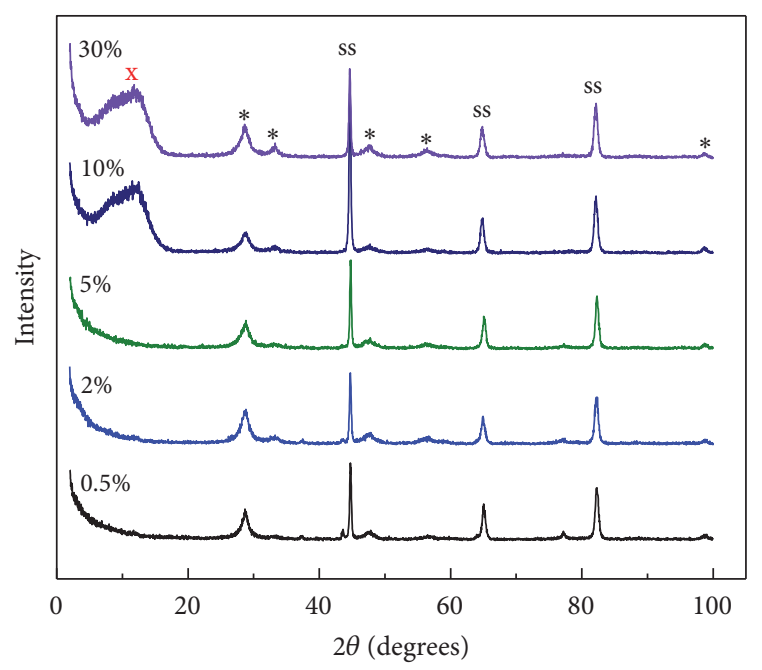

FIGURE 3: X-ray diffraction patterns of $\mathrm{CeO}_{2} / \mathrm{MMT}$ nanocomposite films deposited from $0.5,2,5,10$, and $30 \%$ MMT concentrations in the plating solution $(*$ represents the cerium oxide reflections, and red $\mathrm{x}$ represents the $00 \mathrm{l}$ reflections for the layered silicate).

tends to result in higher fracture toughness. Nanoindentation experiments for nanocomposites with MMT concentrations higher than $1 \%$ were inconclusive. We believe the presence of excess clay on the surface of the coating led to interference 


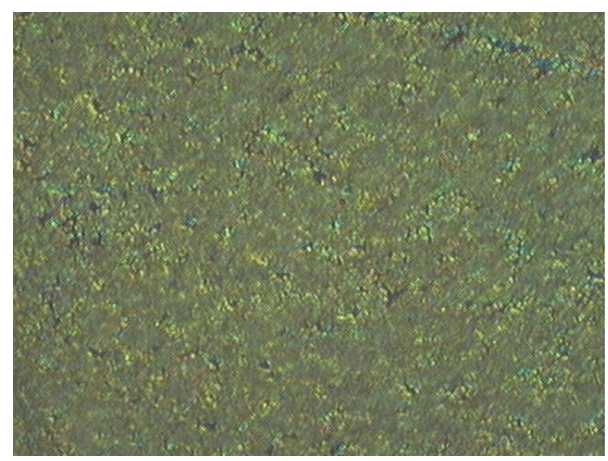

FIgUre 4: Optical picture of a $\mathrm{CeO}_{2} / 5 \% \mathrm{MMT}$ nanocomposite film deposited under potentiostatic conditions at $E=1.10 \mathrm{~V}, 25^{\circ} \mathrm{C}$, and magnification, $\times 800$.

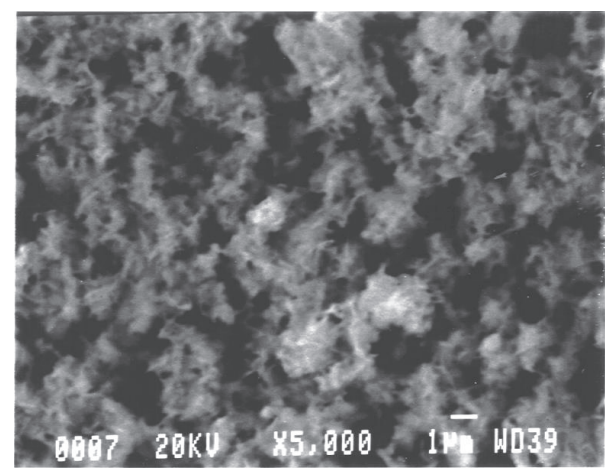

Figure 5: SEM of a $\mathrm{CeO}_{2} / 5 \%$ MMT nanocomposite film.

(sticking) with the nanoprobe tip. Additional mechanical experiments are needed to help elucidate the mechanical properties of the films.

Cross-sectional SEM and EDX were done to validate the incorporation of MMT within the ceramic oxide films. The cross section (Figure 8) displays a layered structure for the film. Interestingly, the film deposits in a layer-by-layer fashion, which could be due to a tendency of the clay platelets to fall face-down onto the electrode, as shown in previous work for a modified electrochemical cell [36]. EDX on the cross section of the composite films reveals the presence of elemental $\mathrm{Ce}, \mathrm{Si}$, and $\mathrm{Al}$, which shows the incorporation of montmorillonite throughout the cerium oxide coating.

A schematic representing the deposition of the nanocomposite coating is shown in Figure 9. Montmorillonite is not electroactive and thus has no redox couple for electrodeposition. Individual clay platelets are produced in solution by $24 \mathrm{hrs}$ of vigorous stirring of the clay suspension. Once the negatively-charged layered silicate is introduced into the plating solution, the clay platelets are countered with positive cerium complex ions. The cerium complex ion in solution is thought to be a weak, predominantly bidentate binding of the cerium ion and suggests a $\left[\mathrm{Ce}\left(\mathrm{H}_{2} \mathrm{O}\right) x\left(\mathrm{O}_{2} \mathrm{CCH}_{3}\right)\right]^{2+}$ species (where $x=6$ or 7) [44]. Kulp et al. also calculated this species as the predominant form in the electrodeposition solution [40]. The cerium ion species is oxidized to form

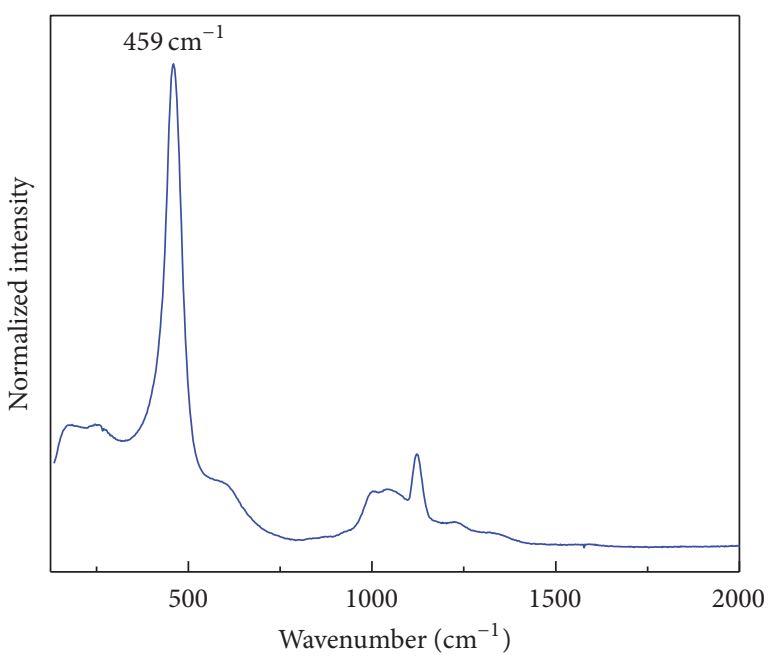

Figure 6: Raman spectra of a $\mathrm{CeO}_{2} / \mathrm{MMT}$ nanocomposite electrodeposited film using potentiostatic conditions at $E=1.10 \mathrm{~V}$ and $25^{\circ} \mathrm{C}$.

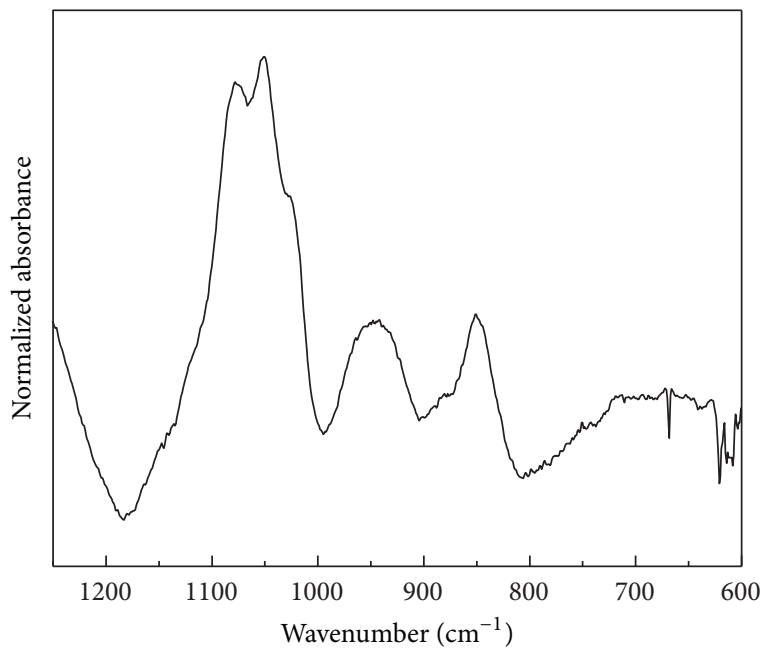

FIgURE 7: ATR-IR spectra of a $\mathrm{CeO}_{2} / \mathrm{MMT}$ nanocomposite electrodeposited film using potentiostatic conditions at $E=1.10 \mathrm{~V}$ and $25^{\circ} \mathrm{C}$.

a coating, while the platelets are believed to concurrently, electrostatically adsorb onto the substrate during deposition. They may reorient on the film's surface to give the most stable arrangement. The planar shape of MMT can produce a tight contact with the charged electrode surface. Crosssectional SEM and EDX confirm this type of deposition for the $\mathrm{CeO}_{2} / \mathrm{MMT}$ nanocomposite coatings.

\section{Conclusions}

Successful electrochemical deposition of $\mathrm{CeO}_{2}$ /layered silicate nanocomposites is accomplished onto metal substrates. The best experimental parameters for synthesis of the nanocomposite films include room temperature deposition, $7.5 \mathrm{pH}$, and $5 \%$ or less of Na-montmorillonite addition. XRD, 


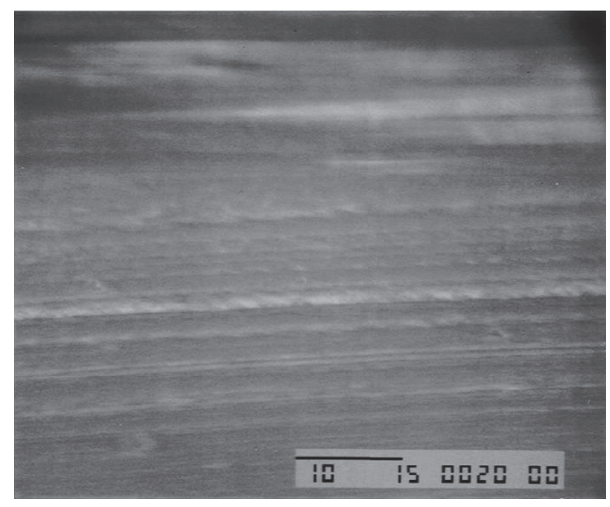

FIGURE 8: Cross-sectional SEM of a $\mathrm{CeO}_{2} / \mathrm{MMT}$ nanocomposite electrodeposited film using potentiostatic conditions at $E=1.10 \mathrm{~V}$ and $25^{\circ} \mathrm{C}$ (bar represents $10 \mu \mathrm{m}$ ).

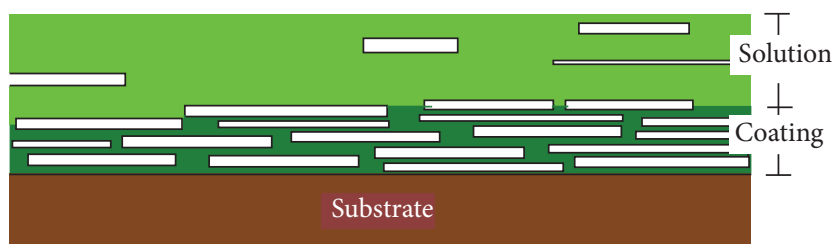

FIGURE 9: Representation of depositing exfoliated layered silicate (white) with cerium ions in solution (light green) and cerium oxide (reduced form in coating is dark green) on a substrate (brown).

FTIR, and Raman spectroscopy indicate that $\mathrm{CeO}_{2}$ is the primary structural matrix of the composite films with particle sizes ranging from 4.50 to $6.50 \mathrm{~nm}$. There is a $23 \%$ increase in modulus for the nanocomposite films. Cross-sectional SEM and EDX confirm that montmorillonite platelets are inserted throughout the matrix of the composites.

\section{Competing Interests}

The authors declare that there are no competing interests regarding the publication of this paper.

\section{Acknowledgments}

The authors acknowledge the Center for Advanced Research and Technology (CART) at the University of North Texas for access to the SEM experimental facilities used for this study. The authors also thank Tauen Analytical for XRD support and AMMPI (Advanced Materials and Manufacturing Processes Institute) at the University of North Texas.

\section{References}

[1] L. G. Ecco, M. Fedel, F. Deflorian, J. Becker, B. B. Iversen, and A. Mamakhel, "Waterborne acrylic paint system based on nanoceria for corrosion protection of steel," Progress in Organic Coatings, vol. 96, pp. 19-25, 2015.

[2] K. Aramaki, "Self-healing protective films prepared on zinc by treatments with cerium (III) nitrate and sodium phosphate," Corrosion Science, vol. 44, no. 11, pp. 2621-2634, 2002.
[3] M. A. Arenas, A. Conde, and J. J. De Damborenea, "Cerium: a suitable green corrosion inhibitor for tinplate," Corrosion Science, vol. 44, no. 3, pp. 511-520, 2002.

[4] D. R. Arnott, B. R. W. Hinton, and N. E. Ryan, "Cationic-filmforming inhibitors for the protection of the AA 7075 aluminum alloy against corrosion in aqueous chloride solution," Corrosion, vol. 45 , no. 1, pp. 12-18, 1989.

[5] H. Hasannejad, T. Shahrabi, A. S. Rouhaghdam, and M. Aliofkhazraei, "Effect of temperature on pitting corrosion resistance of 316 stainless steel coated by cerium oxide film in $3.5 \% \mathrm{NaCl}$ solution," Journal of Materials Science and Technology, vol. 24, no. 5, pp. 715-717, 2008.

[6] E. Stoyanova and D. Stoychev, "Corrosion behavior of stainless steels modified by cerium oxides layers," in Corrosion Resistance, H. Shih, Ed., chapter 11, pp. 239-270, InTech, 2012.

[7] A. Q. Wang and T. D. Golden, "Electrodeposition of oriented cerium oxide films," International Journal of Electrochemistry, vol. 2013, Article ID 482187, 10 pages, 2013.

[8] C. Kleinlogel and L. J. Gauckler, "Sintering and properties of nanosized ceria solid solutions," Solid State Ionics, vol. 135, no. 1-4, pp. 567-573, 2000.

[9] A. I. B. Rondão, N. C. T. Martins, S. G. Patrício, and F. M. B. Marques, "Ionic transport in (nano)composites for fuel cells," International Journal of Hydrogen Energy, vol. 41, no. 18, pp. 7666-7675, 2016.

[10] G. Balakrishnan, C. M. Raghavan, C. Ghosh et al., "Xray diffraction, Raman and photoluminescence studies of nanocrystalline cerium oxide thin films," Ceramics International, vol. 39, no. 7, pp. 8327-8333, 2013.

[11] A. K. Bhosale, S. R. Kulal, V. M. Gurame, and P. S. Patil, "Spray deposited $\mathrm{CeO}_{2}-\mathrm{TiO}_{2}$ counter electrode for electrochromic devices," Bulletin of Materials Science, vol. 38, no. 2, pp. 483-491, 2015.

[12] J. A. Rodriguez, S. Ma, P. Liu, J. Hrbek, J. Evans, and M. Pérez, "Activity of $\mathrm{CeO}_{x}$ and $\mathrm{TiO}_{x}$ nanoparticles grown on $\mathrm{Au}(111)$ in the water-gas shift reaction," Science, vol. 318 , no. 5857, pp. 17571760, 2007.

[13] N. J. Lawrence, J. R. Brewer, L. Wang et al., "Defect engineering in cubic cerium oxide nanostructures for catalytic oxidation," Nano Letters, vol. 11, no. 7, pp. 2666-2671, 2011.

[14] A. Trovarelli, M. Boaro, E. Rocchini, C. De Leitenburg, and G. Dolcetti, "Some recent developments in the characterization of ceria-based catalysts," Journal of Alloys and Compounds, vol. 323-324, pp. 584-591, 2001.

[15] Y. Zhou, R. J. Phillips, and J. A. Switzer, "Electrochemical synthesis and sintering of nanocrystalline cerium(IV) oxide powders," Journal of the American Ceramic Society, vol. 78, no. 4, pp. 981-985, 1995.

[16] J. E. Shemilt, H. M. Williams, M. J. Edirisinghe, J. R. G. Evans, and B. Ralph, "Fracture toughness of doped-ceria ceramics," Scripta Materialia, vol. 36, no. 8, pp. 929-934, 1997.

[17] A. Tschöpe, E. Sommer, and R. Birringer, "Grain size-dependent electrical conductivity of polycrystalline cerium oxide. I. Experiments," Solid State Ionics, vol. 139, no. 3-4, pp. 255-265, 2001.

[18] B. W. Sheldon and W. A. Curtin, "Nanoceramic composites: tough to test," Nature Materials, vol. 3, no. 8, pp. 505-506, 2004.

[19] D. Sciti, L. Pienti, D. D. Fabbriche, S. Guicciardi, and L. Silvestroni, "Combined effect of $\mathrm{SiC}$ chopped fibers and $\mathrm{SiC}$ whiskers on the toughening of $\mathrm{ZrB}_{2}$," Ceramics International, vol. 40, no. 3, pp. 4819-4826, 2014. 
[20] S. Guicciardi, L. Silvestroni, M. Nygren, and D. Sciti, "Microstructure and toughening mechanisms in spark plasma-sintered $\mathrm{ZrB}_{2}$ ceramics reinforced by $\mathrm{SiC}$ whiskers or SiC-chopped fibers," Journal of the American Ceramic Society, vol. 93, no. 8, pp. 2384-2391, 2010.

[21] T.-C. Lee and D. Jianxin, "Ultrasonic erosion of whiskerreinforced ceramic composites," Ceramics International, vol. 27, no. 7, pp. 755-760, 2001.

[22] C. Xu and X. Ai, "Particle dispersed ceramic composite reinforced with rare earth additions," International Journal of Refractory Metals \& Hard Materials, vol. 19, no. 2, pp. 85-88, 2001.

[23] T. Ohji, Y.-K. Jeong, Y.-H. Choa, and K. Niihara, "Strengthening and toughening mechanisms of ceramic nanocomposites," Journal of the American Ceramic Society, vol. 81, no. 6, pp. 14531460, 1998.

[24] C. Kaya, X. Gu, I. Al-Dawery, and E. G. Butler, "Microstructural development of woven mullite fibre-reinforced mullite ceramic matrix composites by infiltration processing," Science and Technology of Advanced Materials, vol. 3, no. 1, pp. 35-44, 2002.

[25] N. P. Bansal and J. A. Setlock, "Fabrication of fiber-reinforced celsian matrix composites," Composites Part A: Applied Science and Manufacturing, vol. 32, no. 8, pp. 1021-1029, 2001.

[26] S. Chen, F. Ye, and Y. Zhou, "Low temperature hot-pressed BAS matrix composites reinforced with in situ grown $\mathrm{Si}_{3} \mathrm{~N}_{4}$ whiskers," Ceramics International, vol. 28, no. 1, pp. 51-58, 2002.

[27] L. Gao, H. Yang, R. Yuan et al., "Sintering and microstructure of silicon nitride with magnesia and cerium additives," Journal of Materials Processing Technology, vol. 115, no. 3, pp. 298-301, 2001.

[28] V. Günay and S. Hampshire, "Processing and properties of pressureless-sintered $\mathrm{Si}_{3} \mathrm{~N}_{4}-\mathrm{SiC}$ composites," Journal of Materials Processing Technology, vol. 54, pp. 348-354, 1995.

[29] Y.-H. Choa, A. Nakahira, and K. Niihara, "Microstructure and mechanical properties of $\mathrm{SiC}$-platelet reinforced $\mathrm{Al}_{2} \mathrm{O}_{3} / \mathrm{SiC}$ particle hybrid composites," Journal of Materials Science, vol. 35, no. 12, pp. 3143-3149, 2000

[30] S.-B. Li, B.-S. Zhang, G.-W. Wen, and J.-X. Xie, "Microstructure and mechanical properties of platelet-reinforced Ti-B$\mathrm{C}$ ceramics prepared by reaction hot pressing of $\mathrm{B}_{4} \mathrm{C}$ and $\mathrm{Ti}$ powders," Materials Letters, vol. 57, no. 8, pp. 1445-1452, 2003.

[31] Y.-S. Han and S. Yamanaka, "Preparation and characterization of microporous $\mathrm{SiO}_{2}-\mathrm{ZrO}_{2}$ pillared montmorillonite," Journal of Solid State Chemistry, vol. 179, no. 4, pp. 1146-1153, 2006.

[32] G. K. Zhang, X. M. Ding, F. S. He et al., "Low-temperature synthesis and photocatalytic activity of $\mathrm{TiO}_{2}$ pillared montmorillonite," Langmuir, vol. 24, no. 3, pp. 1026-1030, 2008.

[33] J.-H. Park, J.-H. Yang, J.-B. Yoon, S.-J. Hwang, and J.-H. Choy, "Intracrystalline structure and physicochemical properties of mixed $\mathrm{SiO}_{2}-\mathrm{TiO}_{2}$ sol-pillared aluminosilicate," The Journal of Physical Chemistry B, vol. 110, no. 4, pp. 1592-1598, 2006.

[34] S.-R. Lee, Y.-S. Han, M. Park, G.-S. Park, and J.-H. Choy, "Nanocrystalline sodalite from $\mathrm{Al}_{2} \mathrm{O}_{3}$ pillared clay by solidsolid transformation," Chemistry of Materials, vol. 15, no. 25, pp. 4841-4845, 2003.

[35] V. A. Drozdov, V. P. Doronin, T. P. Sorokina, T. I. Gulyaeva, and V. K. Duplyakin, "Texture-strength properties of the aluminamontmorillonite composite," Kinetics and Catalysis, vol. 42, no. 1, pp. 117-125, 2001.

[36] R. A. Horch, T. D. Golden, N. A. D’Souza, and L. Riester, "Electrodeposition of nickel/montmorillonite layered silicate nanocomposite thin films," Chemistry of Materials, vol. 14, no. 8, pp. 3531-3538, 2002.

[37] J. Tientong, Y. H. Ahmad, M. Nar, N. D'souza, A. M. A. Mohamed, and T. D. Golden, "Improved mechanical and corrosion properties of nickel composite coatings by incorporation of layered silicates," Materials Chemistry and Physics, vol. 145, no. 1-2, pp. 44-50, 2014.

[38] Y. H. Ahmad, J. Tientong, M. Nar, N. D’Souza, A. M. A. Mohamed, and T. D. Golden, "Characterization and corrosion resistance of electrodeposited Ni-Mo-silicate platelet nanocomposite coatings," Surface and Coatings Technology, vol. 259, pp. 517-525, 2014.

[39] C. R. Thurber, Y. H. Ahmad, S. F. Sanders et al., "Electrodeposition of 70-30 Cu-Ni nanocomposite coatings for enhanced mechanical and corrosion properties," Current Applied Physics, vol. 16, no. 3, pp. 387-396, 2016.

[40] E. A. Kulp, S. J. Limmer, E. W. Bohannan, and J. A. Switzer, "Electrodeposition of nanometer-thick ceria films by oxidation of cerium(III)-acetate," Solid State Ionics, vol. 178, no. 11-12, pp. 749-757, 2007.

[41] S. Wang, W. Wang, J. Zuo, and Y. Qian, "Study of the Raman spectrum of $\mathrm{CeO}_{2}$ nanometer thin films," Materials Chemistry and Physics, vol. 68, no. 1-3, pp. 246-248, 2001.

[42] J. Madejová and P. Komadel, "Baseline studies of the clay minerals society source clays: infrared methods," Clays and Clay Minerals, vol. 49, no. 5, pp. 410-432, 2001.

[43] J. Madejová, "FTIR techniques in clay mineral studies," Vibrational Spectroscopy, vol. 31, no. 1, pp. 1-10, 2003.

[44] M. E. Azenha, H. D. Burrows, S. M. Fonseca et al., "Luminescence from cerium(III) acetate complexes in aqueous solution: considerations on the nature of carboxylate binding to trivalent lanthanides," New Journal of Chemistry, vol. 32, no. 9, pp. 15311535, 2008. 

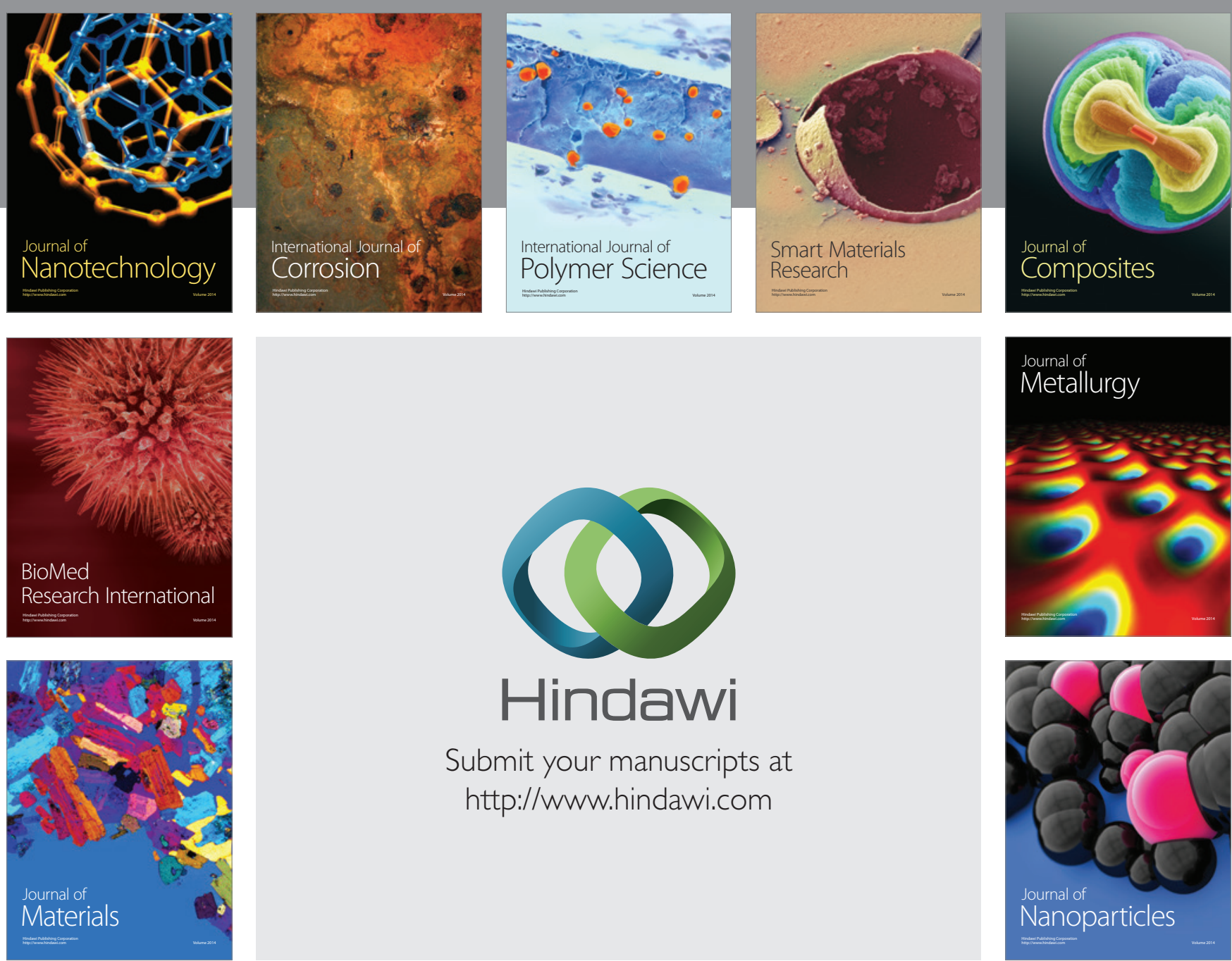

\section{Hindawi}

Submit your manuscripts at

http://www.hindawi.com

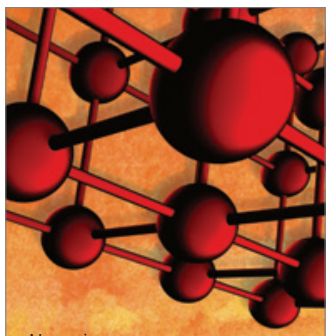

Materials Science and Engineering
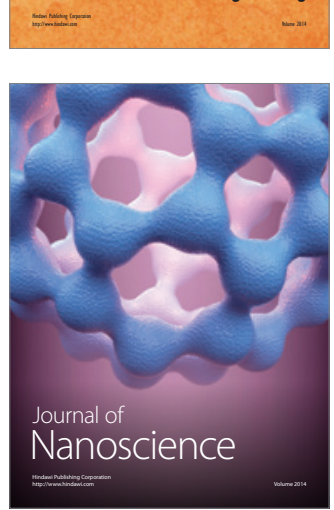
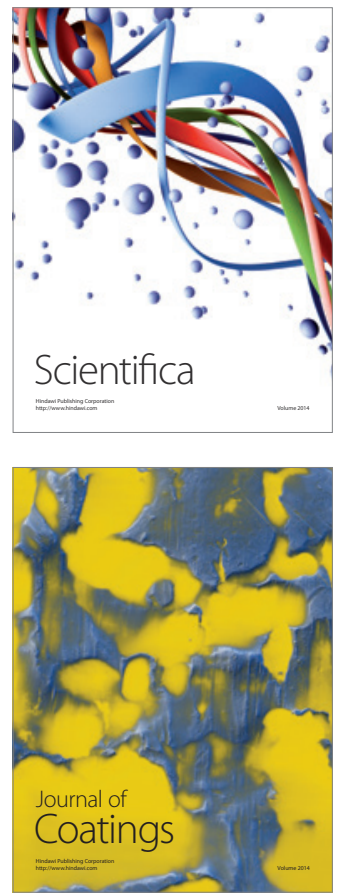
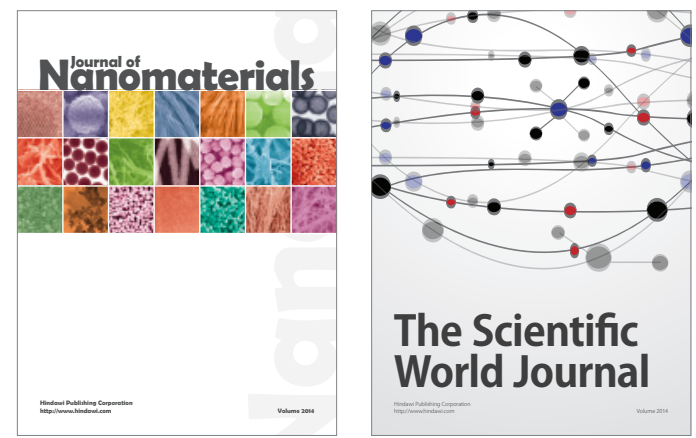

The Scientific World Journal
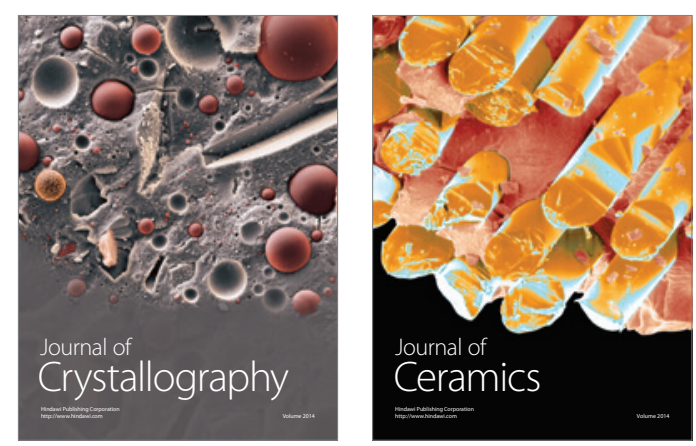
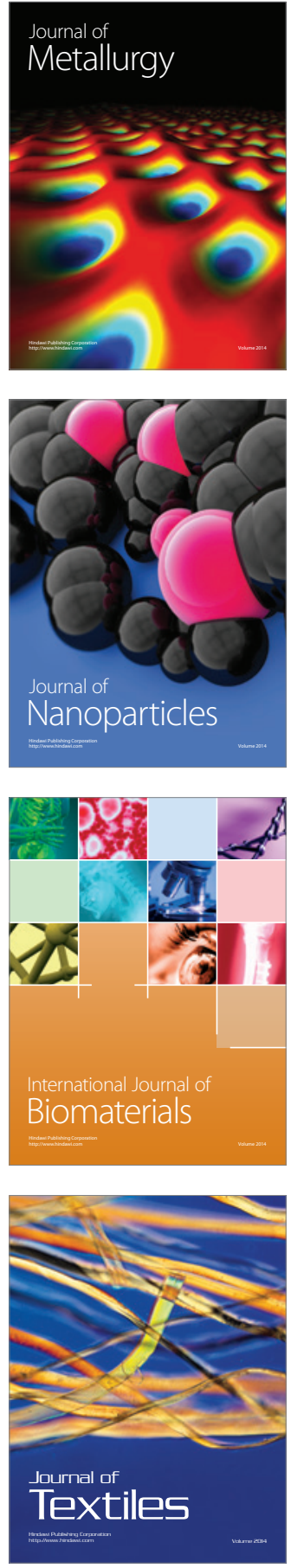